\title{
Giant osteochondroma of the parapharyngeal space: a case report
}

\author{
Chul-Hwan Kim, Yoon-Sun Lee \\ Department of Oral and Maxillofacial Surgery, School of Dentistry, Dankook University, Cheonan, Korea
}

\begin{abstract}
J Korean Assoc Oral Maxillofac Surg 2013;39:35-40)
Osteochondroma is a common benign tumor of the axial skeleton, especially in the distal metaphysis of the femur and the proximal metaphysis of the tibia, that can occur on the facial skeleton (albeit rarely). Osteochondroma is differentiated from chondroma, osteochondromatosis and osteoma. Osteochondroma shows an irregular radiopaque lesion and chondromatic area surrounded by the osteoma. When it develops in the long bone, it has a marked tendency to occur at 10 to 20 years of age and ceases with the end of pubertal growth. However, when it develops in the mandibular condyle, it is prevalent in the third decade and continuous to develop. Tumors that develop in the long bone have a predilection for men, but tumors in the mandible have a predilection for women. In osteochondroma of the mandibular condyle, clinical features presented include occlusal changes, facial asymmetry, headaches, pain and joint noise on the temporomandibular joint, mouth opening limitations, and jaw deviation at the involved site. The first choice of treatment for the massive osteochondroma is surgical removal. A 70-year-old female patient with an osteochondroma on her right mandibular condyle visited our clinic. We surgically removed the mass with favorable results. It is presented here along with a review of literature on osteochondroma.
\end{abstract}

Key words: Osteochondroma, Mandibular condyle, Facial asymmetry

[paper submitted 2012. 2. 28 / revised 1st 2012. 5. 16, 2nd 2012. 5. 24 / accepted 2012. 5. 25]

\section{Introduction}

Osteochondroma is a bone tumor appearing in a bone that is formed as a result of endochondral ossification. It generally occurs mainly in the metaphysis of a long bone, such as femur or tibia. It is a benign tumor that occurs, though rarely, also in the facial skeleton. The areas of its predominant occurrence in the facial skeleton include the coronoid process ${ }^{1}$, the mandibular condyle ${ }^{2}$, the tongue ${ }^{3}$, the maxillary sinus ${ }^{4}$, and the zygoma $^{5}$. It is also known to occur mainly in the mandibular posterior region if its occurrence is, though rarely, in a bone ${ }^{6}$.

This disease appears as a radiopaque lesion that has a relatively clear boundary in a radiograph. Radiopaque tumors

\section{Chul-Hwan Kim}

Department of Oral and Maxillofacial Surgery, School of Dentistry, Dankook University, 119 Dandae-ro, Dongnam-gu, Cheonan 330-714, Korea TEL: +82-41-550-1996 FAX: +82-41-551-8988

E-mail:kimchoms@dankook.ac.kr

(c) This is an open-access article distributed under the terms of the Creative Commons Attribution Non-Commercial License (http://creativecommons.org/licenses/by-nc/3.0/), which permits unrestricted non-commercial use, distribution, and reproduction in any medium, provided the original work is properly cited.

Copyright (C) 2013 The Korean Association of Oral and Maxillofacial Surgeons. All rights reserved. that appear in the mandibular condyle include osteoblastoma, ossifying fibroma, chondroma, and synovial chondromatosis. Since chondrosarcoma or osteosarcoma among the malignant tumors occurs commonly, differential diagnosis of them is required ${ }^{7}$.

Osteochondroma that has occurred in the condylar area may show a variety of symptoms, such as facial asymmetry, posterior open bite, pain in the condylar area during mouth opening, or the temporomandibular joint (TMJ) internal derangement. Morphologically, it may show condylar length increase or condylar hyperplasia, for which traditional therapies include surgical tumor excision, condylectomy, and TMJ reconstruction $^{8}$, and relapses have been rarely reported ${ }^{9}$. About $1-2 \%$ of monostotic osteochondroma in a long bone shows a malignant change as chondrosarcoma, but it is generally known to be without malignant metastasis in the jawbone ${ }^{10}$.

In this case, the patient came to and was received by our hospital due to neck pain during swallowing at the request of another hospital. She had been showing a carbuncle in the right face and a chin deviation to the left side since three years earlier, but she did not show any pain or mouth opening limitation. In a radiological examination of the patient, a giant osseous lesion presumed to be 
osteochondroma was discovered in the mandibular condyle. This department reports that it has satisfactorily treated both giant osteochondroma and facial asymmetry contracted in the mandibular condyle by performing surgical tumor excision through the mandibular swing approach.

\section{Case Report}

A 70-year-old female patient came to and was received by the Department of Oral and Maxillofacial Surgery at Dankook University Dental Hospital due to neck pain during swallowing and an edema on her right face at the request of another hospital. As for her medical history, she had hypertension in terms of her whole body. And complaining of an occlusal disorder as well as an edema on her right face and a chin deviation to the left side which had begun three years earlier, she visited another hospital as mentioned above, which then requested our hospital for examination of her on behalf of it.

In clinical examination, the patient did not show any

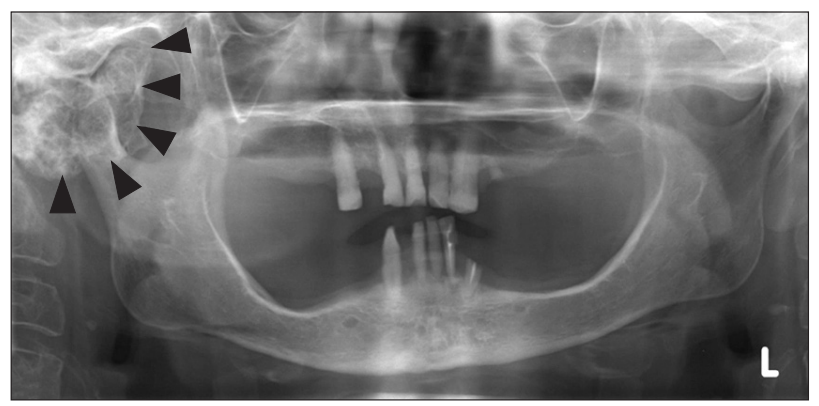

Fig. 1. Initial panoramic view shows round radiopaque mass on the right mandibular condyle with jaw deviation (arowheads).

Chul-Hwan Kim et al: Giant osteochondroma of the parapharyngeal space: a case report. J Korean Assoc Oral Maxillofac Surg 2013 limitation in the amount of mouth opening or any pain in the condylar area. She did not show any unusual symptoms such as mandibular trauma, teeth clenching or teeth grinding. But the end of her chin deviated to the left side. She showed an occlusal disorder which had begun along with a carbuncle on her face. She complained of pain in the right oropharyngeal area when swallowing something or undergoing palpation.

There was nothing unusual detected in the blood test, urinalysis, electrocardiogram, and chest radiograph of the patient.

In a panoramic radiograph, we confirmed a giant radiopaque image suspected of a bone lesion in the right condylar area.(Fig. 1) In an magnetic resonance imaging picture and in computed tomography, we observed an about $5.0 \times 2.5 \mathrm{~cm}$ giant osseous tissue penetrating the parapharyngeal space in the posterior medial direction of the right condylar head, which was then shown to have been pushed laterally as a result of it.(Fig. 2) The shape of the joint disk was relatively normal. In the bone scan using ${ }^{99 \mathrm{~m}} \mathrm{Tc}$, we could see uptake of radioisotopes locally toward inside the right mandibular condyle.(Fig. 3)

We planned to perform surgical tumor excision including some part of the right mandibular condyle on the assumption that the patient had a benign tumor in the right mandibular condyle through comprehensive consideration of the examination results of her medical history and clinical symptoms as well as the radiographic findings in the patient.

Surgery was performed under general anesthesia. An extraoral approach was achieved through lip split incision and extension of the incision line on the inferior margin area of the right mandible in order to secure easy access to and a field of view of the parapharyngeal space in the posterior medial part of the condylar head where the lesion was located

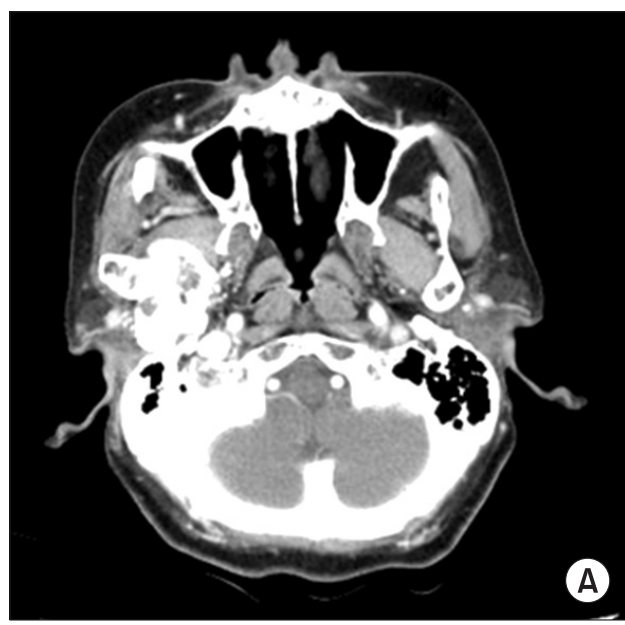

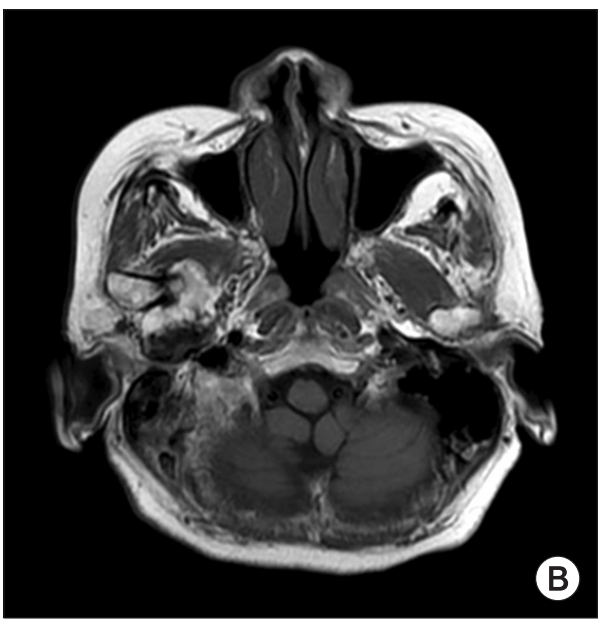

Fig. 2. Preoperative computed tomography (A), magnetic resonance imaging (B). Axial view shows mass invaded right parapharyngeal space.

Chul-Hwan Kim et al: Giant osteochondroma of the parapharyngeal space: a case report. J Korean Assoc Oral Maxillofac Surg 2013 

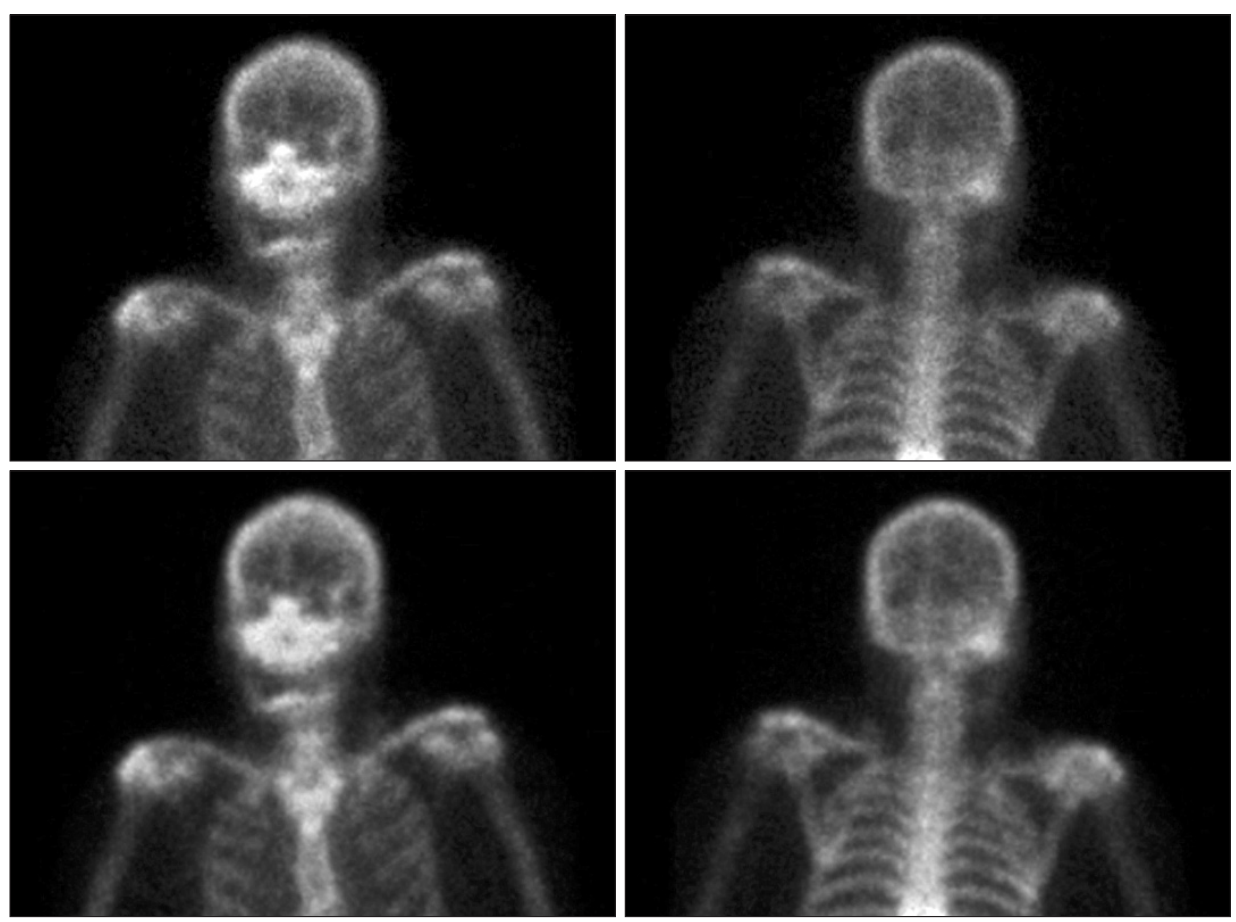

Fig. 3. ${ }^{99 \mathrm{~m}} \mathrm{Tc}$ bone scan. There is a focal hot spot in the right mandibular condyle.

Chul-Hwan Kim et al: Giant osteochondroma of the parapharyngeal space: a case report. J Korean Assoc Oral Maxillofac Surg 2013
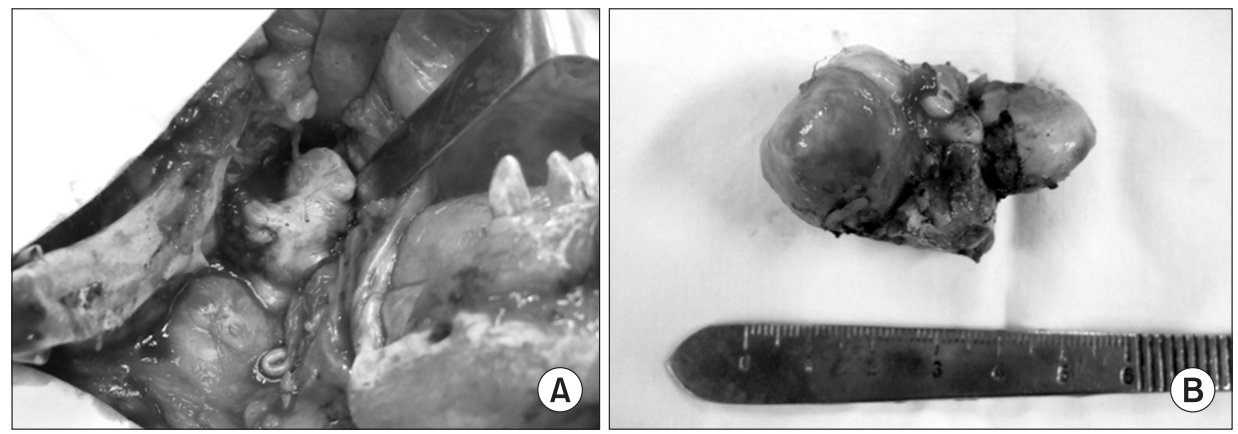

Fig. 4. Intraoperative finding. A. Exposure hard tumor mass in skull base via lip-split incision. B. $5 \times 3 \times 3 \mathrm{~cm}$ size bony mass was removed.

Chul-Hwan Kim et al: Giant osteochondroma of the parapharyngeal space: a case report. J Korean Assoc Oral Maxillofac Surg 2013

and also obtain a space for excision of the giant tumor. In addition, mandibulotomy was performed in the mandibular molar area, followed by lateral displacement of the cut bone fragment. The condylar head had been separated from the skull base, and there was neither deformation nor perforation of the joint disk. The mesial articular eminence portion was removed together with the periosteums around the tumor and the cartilage in the superior area using condylectomy.(Fig. 4. A)

The excised tumor was $5 \times 3 \times 3 \mathrm{~cm}$ in size and its satisfied was lined by cartilaginous tissue. Its boundary was unclear and continuous with the inferior bone.(Fig. 4. B) In the histopathological findings from the tissue at low magnification, we could see the bone portion in the interior area and the cartilagious cap in the superior area and also observe endochondral ossification between the bone and the cartilage.(Figs. 5. A, 5. B) Accordingly, we finally confirmed the osteochondroma that had occurred in the mandibular condyle.

Although a little amount of facial asymmetry remained due to the right-sided unilateral hypertrophy of the mandibular bone after condylectomy, the patient did not want any more improvement on it, and we confirmed removal of the tumor that had occupied the posterior medial part of the right condylar head in the computed tomography performed after the surgical operation.(Figs. 6, 7) Active physical treatment was conducted for three weeks after the surgery. The temporary mandibular movement disorder and pain that had occurred immediately after the surgery disappeared.

\section{Discussion}

There are various theories regarding the pathological occurrence and causes of osteochondroma. Langenskiöld ${ }^{11}$ insisted in 1967 that osteochondroma occurs in the wake of 

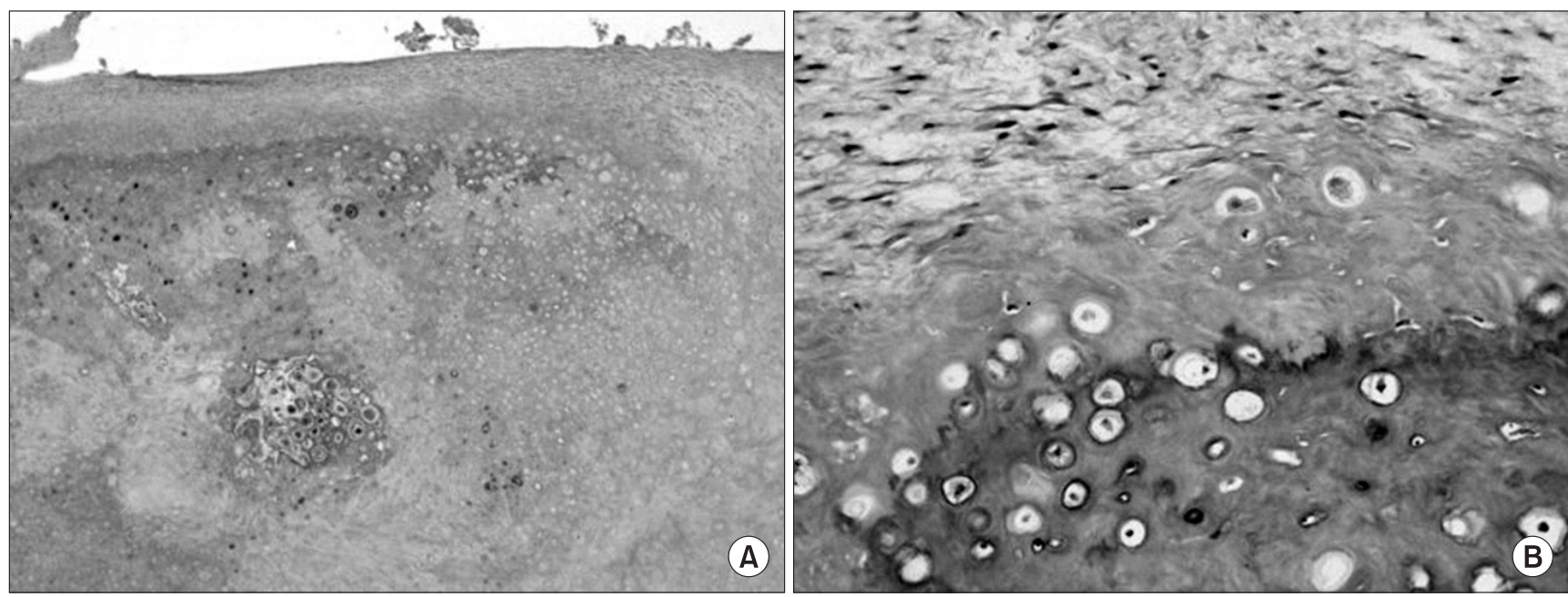

Fig. 5. A. Photomicrograph shows cartilaginous cap and endochondral ossification. B. Magnification of the area of endochondral ossification. (H\&E staining, A: $\times 40, B: \times 100)$

Chul-Hwan Kim et al: Giant osteochondroma of the parapharyngeal space: a case report. J Korean Assoc Oral Maxillofac Surg 2013

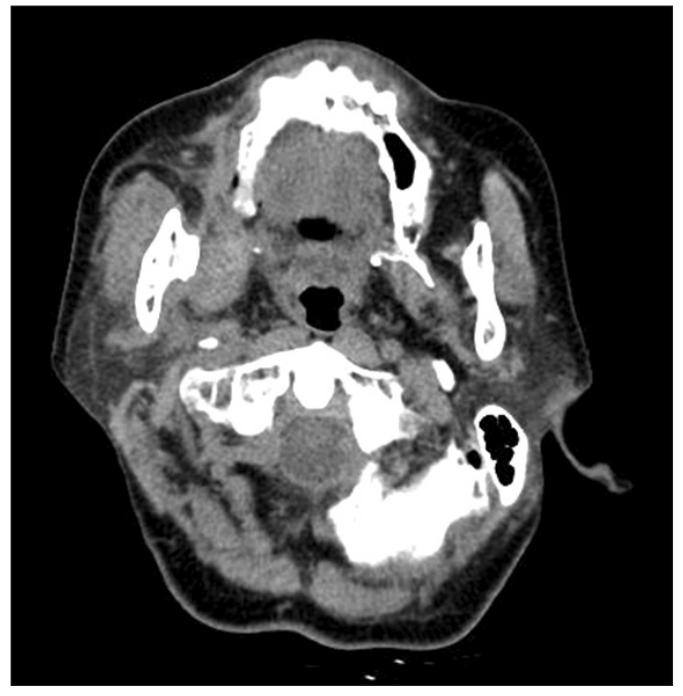

Fig. 6. Postoperative computed tomography. Axial view. Chul-Hwan Kim et al: Giant osteochondroma of the parapharyngeal space: a case report. J Korean Assoc Oral Maxillofac Surg 2013

proliferation of undifferentiated cell layers in the epiphyseal area and the following inferior displacement of these cells onto the metaphyseal area. This can explain a lesion around the condylar head but cannot explain a lesion that occurs in a membranous bone such as a maxillary bone ${ }^{12}$.

In 1974, Allan and Scott ${ }^{13}$ explained most osteochondromas that occur in the mandible as reactive hyperplasia or developmental disorders. In 1951, Lichtenstein ${ }^{7}$ said that osteochondroma occurs in the wake of endochondral ossification that follows the formation of cartilage due to the natural or induced metaplasia of the periosteum that can form osteoblast and chondroblast. This is a hypothesis that

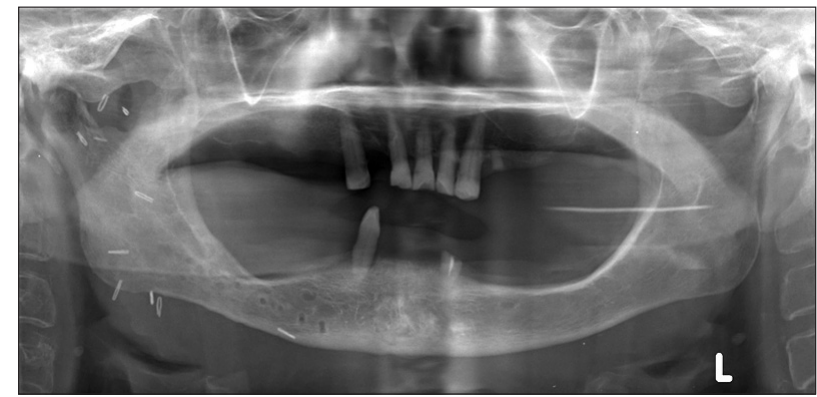

Fig. 7. Postoperative panorama view.

Chul-Hwan Kim et al: Giant osteochondroma of the parapharyngeal space: a case report. J Korean Assoc Oral Maxillofac Surg 2013

can explain the osteochondroma that has occurred in the extracondyle area where no tendon exists. In 1982, Kaneda et al. ${ }^{14}$ announced that trauma and infection serve as causative factors in the formation of osteochondroma in the mandibular condyle.

Although a lot of hypotheses have been announced on the occurrence mechanism of osteochondroma so far, debate is still underway as to whether osteochondroma is indeed a developmental problem, whether it is a true neoplasm, or whether it is a simple exuberant repair activity. In most cases, the growth of osteochondroma occurs in proportion to skeletal growth ${ }^{13}$. In the case of a long bone, once its growth ends, the growth of the tumor will also end. In the case of the mandibular condyle, however, the tumor continues to grow ${ }^{15}$, and the continuous growth of the tumor in the mandibular condyle may be due to the continuous stimulus from the tendon during mandibular movement ${ }^{16}$.

The osteochondroma occurring in a long bone and the 
osteochondroma occurring in the craniofacial area are more or less different. In the case of a long bone, osteochondroma occurs regardless of sex or tends to occur a little more often in male persons. It occurs in people in their relatively early years with the average age of 20 years, and being often asymptomatic, it is observed without surgery ${ }^{10}$. On the other hand, in the case of the jawbone, osteochondroma tends to occur predominantly in female persons, and the average age of onset is high -40 years ${ }^{9}$. Osteochondroma contracted in the mandibular condyle often leads to functional and cosmetic abnormalities, thus needing to be removed ${ }^{9,10}$.

Osteochondroma is either monostotic or polyostotic, and $90 \%$ of all the cases of osteochondroma are monostotic. Monostotic osteochondroma shows the occurrence rate of $60 \%$ in people in their teens to thirties, and its malignant metastasis is less than $1 \%$. It is known that there are hereditary factors in the case of polyostotic osteochondroma, which occurs mostly in people of not more than 20 years of age, with its occurrence being more frequent in male persons than in female persons by the ratio of three to one ${ }^{15}$.

The bony part and the cartilaginous part are largely mentioned by histological classification. The bony part consists of regular bony trabeculas formed by endochondral ossification, and you can see the activity of osteoblasts there. The cartilaginous part that covers this bone consists of hyaline cartilages with various thicknesses and has chondrocysts arrayed in parallel, with an average thickness of $6 \mathrm{~mm}^{13,17}$. These histological findings are similar to the histological findings of the mandibular condyle prior to the completion of endochondral ossification. Histologically, osteochondroma needs to be distinguished from ostoma, benign osteoblastoma, chondroma and chondroblastoma ${ }^{18}$.

Most cases of osteochondroma having occurred in the mandibular condyle are unilateral, and it is located in the anterior medial part of the mandibular condyle. Tumor may be accelerated along with such related clinical symptoms as a posterior open bite on the affected side, a reversed occlusion on the non-affected side, a horizontal maxillary incline that occurs in compensation for the increased vertical dysplasia of the mandible, a masticatory disorder, and/or anterior protrusion of the jaw joint and the accompanying facial asymmetry. It may also be accompanied by jaw joint symptoms, such as jaw joint pain, a mandibular movement disorder, crepitation, a headache, and/or neck pain.

Also in this case, like the general osteochondroma of the mandibular condyle, osteochondroma was contracted in the unilateral mandibular condyle and accompanied by such typical symptoms as the vertical dysplasia of the mandible, a facial asymmetry and a masticatory disorder.

Surgical tumor excision, condylectomy, or mandibular vertical osteotomy accompanied by condylectomy is used for treatment of osteochondroma that has occurred in the condylar head. Surgical tumor excision is used to remove only abnormal tumors which exist in the condylar head and includes the preauricular approach, the posterior medial approach, and tumor excision performed by following the articular $\operatorname{arch}^{19}$. In the case of removal of tumors using surgical tumor excision, Vezeau et al. ${ }^{17}$ reported as follows: If a tumor is located in the anterior medial part of the condylar head, some part of the tumor may remain in the form of a spur, but a satisfactory result my be obtained after pursuit and observation of it for a long time. Condylectomy is a safe and sure method for treatment of osteochondroma. It is used to remove the tumor and the normal bone tissue together, and the scope of tumor excision varies depending on the size and location of the tumor and the condition of the joint disk. If the size of the tumor is small and its location is limited to the condylar area, excision of the tumor in the inferior part of the condylar head is used. If the size of the tumor is large and the position and form of the joint disk are good, the tumor is removed by performing oblique osteotomy in the superior part of the of the mandible and then the part of oblique osteotomy is placed back in its original position after tumor removal. If the condylar head cannot be conserved when the tumor is excised, it is also possible to immediately reconstruct it using an artificial condylar prosthesis ${ }^{20}$. Vertical osteotomy accompanied by condylectomy is a very efficient treatment method for osteochondroma where there is a facial asymmetry, an abnormal position of the joint disk or a pain in the condylar head during mastication.

This case was a giant osteochondroma that infiltrated the right parapharyngeal space, for which tumor excision accompanied by condylectomy was performed using the mandibular swing approach in order to secure easy access to, a field of view of, and a space for excision of the giant tumor in the parapharyngeal space in the posterior medial part of the condylar head where the lesion was located, instead of using the preauricular approach, the postauricular approach and excision performed by following the articular arch, which are generally used for removal of osteochondroma, and as a result we obtained satisfactory results, including improvement of the posterior open bite and alleviation of the chronic pain. From now on, periodical clinical course observation of this case is required for future evaluation of 
the prognosis after removal of the osteochondroma.

\section{References}

1. Meyer RA. Osteochondroma of coronoid process of mandible: report of case. J Oral Surg 1972;30:297-300.

2. Huh HY, Jo SG, Jin WJ, Shin HK, Kim OW. Cases report of surgical correction of unilateral osteochondroma. J Korean Acad Oral Surg 1987;13:57-66.

3. Landini G, Kitano M, Urago A, Sugihara K, Yamashita S. Chondroma and osteochondroma of the tongue. Oral Surg Oral Med Oral Pathol 1989;68:206-9.

4. Traub DJ, Marco WP, Eisenberg E, Barrows G. Osteochondroma of the maxillary sinus: report of a case. J Oral Maxillofac Surg 1990;48:752-5.

5. Pool JW, Tilson HB, Thornton WE, Steed DL. Osteochondroma of the zygomatic arch: report of case. J Oral Surg 1979;37:673-5.

6. Barnes L. Surgical pathology of the head and neck. New York: Dekker; 1985.

7. Lichtenstein L. Classification of primary tumors of bone. Cancer 1951;4:335-41.

8. Marx RE, Stern D. Oral and maxillofacial pathology : a rationale for diagnosis and treatment. Chicago: Quintessence; 2003:772.

9. Peroz I, Scholman HJ, Hell B. Osteochondroma of the mandibular condyle: a case report. Int J Oral Maxillofac Surg 2002;31:455-6.

10. Gaines RE Jr, Lee MB, Crocker DJ. Osteochondroma of the mandibular condyle: case report and review of the literature. J Oral
Maxillofac Surg 1992;50:899-903.

11. Langenskiöld A. The development of multiple cartilaginous exostoses. Acta Orthop Scandinav 1967;38:259-66.

12. Kim MS, Lee MH, Jang CS, Kim CH. A case report of osteochondroma on mandibular condyle. J Korean Assoc Maxillofac Plast Reconstr Surg 1996;18:298-307.

13. Allan JH, Scott J. Osteochondroma of the mandible. Oral Surg Oral Med Oral Pathol 1974;37:556-65.

14. Kaneda T, Torii S, Yamashita T, Inoue N, Shimizu K. Giant osteochondroma of the mandibular condyle. J Oral Maxillofac Surg 1982;40:818-21.

15. Huvos AG. Bone tumors, diagnosis, treatment, and prognosis. Philadelphia: Saunders; 1979:139-60.

16. Forssell H, Happonen RP, Forssell K, Virolainen E. Osteochondroma of the mandibular condyle. Report of a case and review of the literature. Br J Oral Maxillofac Surg 1985;23:183-9.

17. Vezeau PJ, Fridrich KL, Vincent SD. Osteochondroma of the mandibular condyle: literature review and report of two atypical cases. J Oral Maxillofac Surg 1995;53:954-63.

18. Henry CH, Granite EL, Rafetto LK. Osteochondroma of the mandibular condyle: report of a case and review of the literature. J Oral Maxillofac Surg 1992;50:1102-8.

19. Marks RB, Carlton DM Jr, Carr RF. Osteochondroma of the mandibular condyle. Report of a case with 10-year follow-up. Oral Surg Oral Med Oral Pathol 1984;58:30-2.

20. Brady FA, Sapp JP, Christensen RE. Extracondylar osteochondromas of the jaws. Oral Surg Oral Med Oral Pathol 1978;46:65868. 